\title{
More than one way to describe a problem
}

In popular usage, "hunger" can mean anything from stomach pangs after skipped lunch to famine which takes a devastating toll in human lives.

Today many experts believe a more useful term is "food insecurity." Those involved in hunger research say "food insecurity" is a broader term that encompasses not only the physical manifestations of hunger but such social issues as the availability and affordability of food.

This wider definition enables people to work on longer-term solutions. Hunger is seen not in isolation but as part of a continuum ranging from food security, to insecurity and hunger. "Food insecurity," for example, would describe a household where food supplies are limited. In this situation, families adopt strategies for survival that include smaller portions; smaller meals, or stretching meals by modifying ingredients. As the situation worsens, the level of food insecurity increases. Adults start cutting back on amounts or skipping meals entirely. There might be two to three different levels of food insecurity before the family reached a level where they can be said to be experiencing hunger.

Food security requires that a variety of foods be available through normal channels - not at soup kitchens or food pantries. It also requires that food be accessible both economically and geographically. If the grocery store is three miles away and there is no means of transportation or money to buy food, then it is not considered accessible.

The food must also be nutritionally adequate and safe. It is extremely diffi- cult to buy nutritionally adequate food at a neighborhood convenience or liquor store. The source of the food must also be reliable.

Food insecurity means there is not ready access to nutritious, safe, acceptable food through regular means. There must also be choice. A household is insecure in its food supply if there are only potatoes to eat. Having to rely on charities such as emergency food pantries or soup kitchens is an indication of food insecurity.

Hunger is sometimes defined as a condition in which people lack the basic food calories and nutrients needed for fully active, healthy lives. Undernutrition refers to inadequate intake of food energy (measured by calories) and malnutrition is a failure to obtain nutrient requirements. Most hunger in this country is cyclical, occurring the last 2 weeks of the month when paychecks and food stamps run out.

Poverty guidelines originated in the 1960 s when the federal government designed the "economy food plan," which consisted of a minimally adequate market basket of staple foods. Using the 1955 USDA Survey of Food Consumption, it was determined that an average family of three spent approximately one-third of its income on food. Therefore, any family which was spending the average one-third on food, but found the amount was too small to purchase the minimal-diet food plan, could be classified as poor. The poverty line has been adjusted yearly, using the Consumer Price Index (CPI), and accounting for family size.

In 1993, 39.3 million people in the United States (15\% of the population) lived below the poverty level. - Editor religious agencies undertook a research project to survey people standing in line for free food in Contra Costa County.

The Hunger Task Force undertook a systematic assessment of the county's hunger problem in 1987 and again in 1992. For both studies, they compiled county statistics indicating the number of people served by charitable and public food assistance programs from soup kitchens to school lunch programs. Task force members then interviewed more than 325 people who received free food from emergency food pantries, soup kitchens and USDA commodity distribution sites. These emergency food recipients were asked to provide information about their housing, health and general economic situations, as well as why they asked for help and how often they or members of their family went to bed hungry.

The results of the studies were disturbing. While the numbers of people going hungry do not nearly equal those of counties such as Los Angeles, which have large urban areas, it is evident that hunger exists and is increasing in an area previously considered immune to such problems. Emergency food pantries, which provide recipients with a 3-day supply of food, had already seen a $39 \%$ increase in the numbers they were serving from 198587 ; by 1987 , they were serving 5,240 people per month. Three new soup kitchens opened that year, bringing to eight the total number of places where families could come for a hot meal. Of those eight, four served meals daily or during weekdays, while the other half offered meals much less often.

In 1987, these soup kitchens were already serving twice to three times the anticipated number of people an estimated 900 per month. The USDA commodity distribution sites were handing out a relatively attractive basket of food, including 5-pound blocks of American cheese, to 13,000 people per month.

By 1992, the situation had worsened noticeably, especially for children. Although fewer people lined up for food dispensed at USDA sites $(11,600$ compared to 13,000 five years earlier) the food bags were smaller 